\title{
Biomechanical Significance of Tympanic Bulla in Animals and Birds
}

\author{
S.Sathapathy, S.K.Joshi, S.P.Khandate, R.S.Dalvi, S.K.Jadhav and S.Gohain \\ Department of veterinary Anatomy \& Histology, Nagpur Veterinary College, M. A. F. S. U, Nagpur-440006, \\ Maharashtra, India
}

\begin{abstract}
The present study was conducted on some animals (Ox, Dog, Leopard, Nilgai, Deer and Jackle) and birds (Emu, Peacock, Duck and Vulture) on the tympanic bulla. The latero-medial and rostro-caudal dimensions of tympanic bulla were measured. The tympanic bulla was found more oval and prominent in canines and felines and its probable biomechanical role is suggested.
\end{abstract}

Key words: Biomechanics, Tympanic bulla

\section{Introduction}

The tympanic bulla is an important part of temporal bone located at the base of skull on caudo-ventral aspect adjacent to basioccipital bone (Nickel et al. 1986). Wide variation in morphology is evident in tympanic bulla in different domestic and wild animals (Ox, Dog, Leopard, Nilgai, Deer and Jackle) including birds (Emu, Peacock, Duck and Vulture). The present study is conducted to explore the osteometry of tympanic bulla with its probable function.

\section{Materials And Methods}

For the present study, heads of different animals and birds like Ox, Dog, Leopard, Nilgai, Deer, Jackle, Emu, Peacock, Duck and Vulture were collected after the postmortem examination after their natural death. They were macerated in cold water, sun dried and the latero-medial and rostro-caudal dimensions of tympanic bulla were recorded.

The measurements of dimensions of tympanic bulla of above animals and birds were recorded on scale and Vernier's calliper.

\section{Results And Discussion:}

The dimensions of tympanic bulla in some animals and birds were compared and it was laterally compressed structure in bovines, roughly triangular in birds and a very well prominent oval structure in canines and felines (Table 1). The prominent growth of tympanic bulla is attributed to the wide expansive hollow space in the tympanic bulla serving as an natural balancing mechanism of head during speedy movements or during flying.

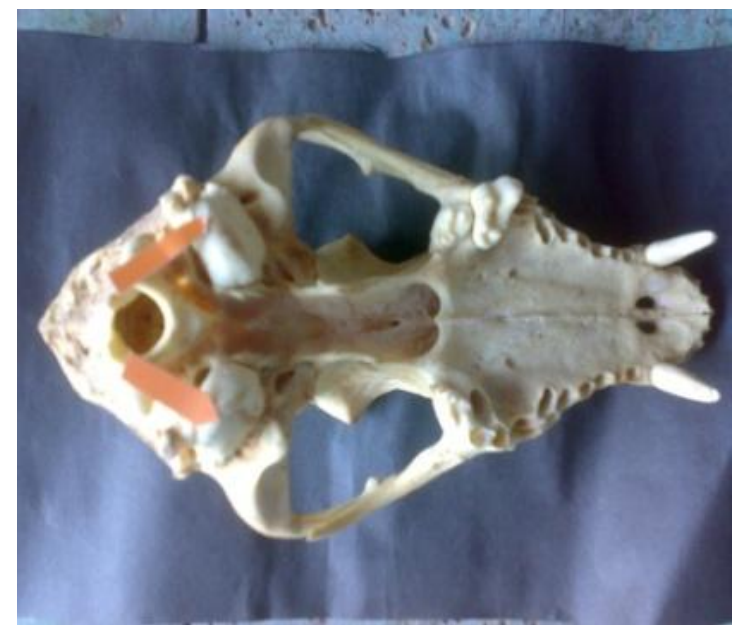

Fig. 1 : A photograph of skull of dog showing the tympanic bulla (Arrow). 


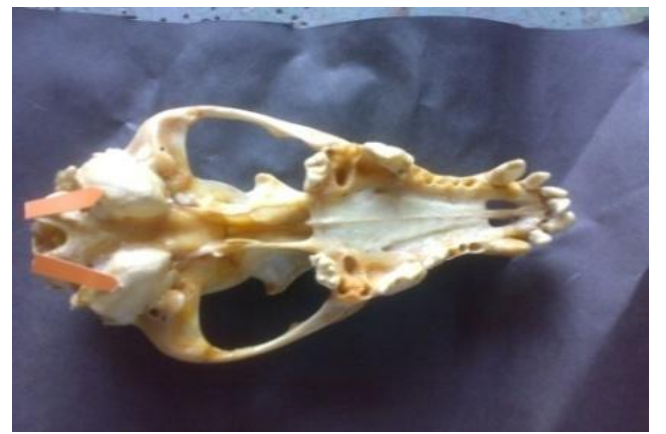

Fig. 2 : A photograph of skull of dog showing the tympanic bulla (Arrow).

Table 1: Measurements of Tympanic bulla

\begin{tabular}{|c|c|c|c|c|}
\hline ANIMALS & \multicolumn{2}{|c|}{$\begin{array}{c}\text { LATERO-MEDIAL } \\
\text { DIMENSION (IN CM) }\end{array}$} & \multicolumn{2}{c|}{$\begin{array}{c}\text { ROSTRO-CAUDAL } \\
\text { DIMENSION (IN CM) }\end{array}$} \\
\hline & MEAN & $\begin{array}{c}\text { STANDARD } \\
\text { ERROR }\end{array}$ & MEAN & $\begin{array}{c}\text { STANDARD } \\
\text { ERROR }\end{array}$ \\
\hline OX & 4.4 & 0.992 & 4.7 & 1.053 \\
\hline DOG & 2.44 & 0.632 & 2.26 & 0.632 \\
\hline LEOPARD & 3.1 & 0.856 & 4.1 & 0.992 \\
\hline NILGAI & 2.8 & 0.707 & 3.4 & 0.856 \\
\hline DEER & 2.6 & 0.707 & 2.9 & 0.780 \\
\hline JACKLE & 3.1 & 0.856 & 3.4 & 0.856 \\
\hline EMU & 1 & 0.484 & 2 & 0.661 \\
\hline PEACOCK & 0.8 & 0.330 & 0.8 & 0.330 \\
\hline DUCK & 0.7 & 0.330 & 0.8 & 0.330 \\
\hline VULTURE & 0.9 & 0.433 & 1.7 & 0.5 \\
\hline
\end{tabular}

\section{Conclusion:}

Tympanic bulla of different animals and birds under study had varied morphology and were very well developed in canines and felines indicating their biomechanical role in balancing mechanism of head.

\section{Acknowledgements:}

I am very much thankful to my coauthors, especially to Dr. R. S. Dalvi, Professor \& Head, Nagpur Veterinary College, Nagpur.

\section{References:}

[1] Nickel, R., Schummer, A., Seifrle, E. 1986. Skeleton of head of ruminants. In : The Anatomy of Domestic Animals, Vol. 1, Verlag Paul Parey, Berlin, pp. 151. 